\title{
HUBUNGAN JARAK KELAHIRAN DENGAN PENGASUHAN TUMBUH KEMBANG ANAK BALITA DI PROVINSI SUMATERA UTARA (ANALISIS DATA SEKUNDER SRPJMN 2017)
}

\author{
*Asrul', Faradita Wahyuni', Muhammad Ancha Sitorus ${ }^{2}$ \\ ${ }^{1}$ Dosen D4 Kebidanan Institut Kesehatan Helvetia Medan, asrul.alzabbar@gmail.com \\ 2Peneliti BKKBN Provinsi Sumatera Utara, ancha.sitorus@gmail.com
}

\section{INFO ARTIKEL}

Riwayat Artikel:

Diterima: 12-06-2019

Disetujui: 11-07-2019

\section{Kata Kunci:}

Birth Span

Parenting

Child Growth and

Development

\begin{abstract}
ABSTRAK
Abstrak: Seribu hari pertama kelahiran setiap anak merupakan masa perkembangan kecerdasan yang sangat pesat pada setiap individu sehingga masa ini disebut golden age (masa emas). Anak-anak yang lahir dengan jarak kelahiran 3 sampai 5 tahun dengan kelahiran sebelumnya memiliki tingkat kelangsungan hidup 2,5 kali lebih tinggi dari pada mereka yang lahir dengan jarak kelahiran < 2 tahun. Anak-anak yang lahir dengan jarak kelahiran 3 tahun dengan kelahiran sebelumnya lebih sehat saat mereka dilahirkan dan memiliki kemungkinan hidup lebih baik pada setiap pertumbuhan dan perkembangannya. Tujuan dari analisis ini adalah untuk melihat hubungan jarak kelahiran dengan pengasuhan tumbuh kembang anak di sumatera utara. Analisis ini menggunakan data sekunder, yaitu data dari "Survei Indikator Kinerja Rencana Pembangunan Jangka Menengah Nasional (RPJMN) Program Kependudukan dan Keluarga Berencana Tahun 2017". Survei dilaksanakan di semua kabupaten (34 kabupaten) disumatera utara. Responden adalah WUS yang memiliki anak balita dengan usia 0-4 tahun dengan jarak kelahiran anak terakhir dengan anak sebelumnya adalah 339. Hasil uji chi square diperoleh nilai sig 0.201 yang menunjukkan bahwa tidak ada hubungan jarak kelahiran dengan pengasuhan tumbuh kembang anak di sumatera utara. Hal ini membuktikan bahwasanya tidak ada perbedaan pengasuhan orang tua baik pada jarak kelahiran pendek maupun jarak kelahiran yang panjang. Menurut asumsi peneliti, hal ini terjadi dikarenakan orangtua tidak terlalu mementingkan pengasuhan tumbuh kembang anak yang meliputi aspek pertumbuhan fisik, aspek jiwa/metal/spiritual dan aspek sosial. Namun orangtua lebih mementingkan aspek finansial atau keuangan untuk bertahan hidup mereka. Sehingga pola asuh menjadi terabaikan.
\end{abstract}

\begin{abstract}
The first 1000 days of birth for each child is a period of very rapid development of intelligence in each individual so that this period is called the golden age. Children born with birth spans of 3 to 5 years with previous births have a sustained rate of life of 2.5 times higher than those who live at birth $<2$ years. Children who were born with the birth spans of three years with the previous births healthier when they were born and have the possibility of living better in every growth and development. The purpose of this analysis is to look at the relationship between birth spans and nurturing child growth and development in North Sumatera. The analysis used the secondary, namely "Indicators Survey of National Medium-Term Development Planning (RPJMN) of Population and Family Planning Program in 2016". The survey conducted in all districts (34 districts) in North Sumatera. Respondents were WUS who had toddler aged 0-4 years with the birth spans of the last child with the previous child was 339. The results of the chi-square test obtained a value of sig 0.201 which indicates that there is no relationship between birth spans and nurturing child growth and development in North Sumatera. This proved that there was no difference in parenting both in short birth spans and long birth spans. According to the researchers' assumptions, this occurs because parents did not place too much importance on nurturing children's growth and development which includes aspects of physical growth, soul /mental/spiritual aspects and social aspects. But parents were more concerned with financial aspects to survive. So that parenting becomes neglected.
\end{abstract}




\section{A. LATAR BELAKANG}

Seribu hari pertama kelahiran setiap anak merupakan masa perkembangan kecerdasan yang sangat pesat pada setiap individu sehingga masa ini disebut golden age (masa emas). Masa ini merupakan masa dasar pertama dalam mengembangkan berbagai kegiatan dalam rangka pengembangan potensi, sikap, keterampilan, kreativitas, kemampuan berbahasa dan kesadaran sosial [1]. Menyadari akan pentingnya pembinaan tumbuh kembang anak sejak dini, Badan Kependudukan dan Keluarga Berencana Nasional (BKKBN) telah mencanangkan Program Bina Keluarga Balita (BKB) sejak tahun 1984, dan pada tahun 1991 program ini berkembang menjadi Gerakan BKB. Penyelenggaraan BKB merupakan upaya untuk meningkatkan pengetahuan dan keterampilan orangtua dalam membina tumbuh kembang anak secara utuh dan optimal, melalui pemberian stimulasi fisik, kognitif, sosioemosional dan spiritual [2].

Pengasuhan berasal dari kata asuh yang mempunyai makna menjaga, merawat, dan mendidik anak yang masih kecil selain itu juga pola asuh dirumuskan sebagai seperangkat sikap dan perilaku yang tertata baik yang diterapkan oleh orang tua dalam berinteraksi dengan anaknya [3]. Hurlock (1999) menyatakan bahwa pola asuh orang tua adalah metode yang digunakan orang tua dalam hubungannya dengan anaknya, selain itu pola asuh juga dapat diartikan sebagai cara, bentuk atau strategi dalam pendidikan keluarga yang dilakukan orang tua kepada anaknya. Sehingga anak balita harus mendapat pola asuh dari pemenuhan kebutuhan fisik maupun psikososial, sandang, pangan, gizi, pengobatan cepat dan tepat serta perawatan kesehatan dasar [4]. Peran Keluarga dalam hal ini orangtua merupakan wadah lingkungan universal yang utama dan pertama bagi setiap anak untuk belajar makan, berjalan, berbicara, dan mengenal identitas dan berbagai perilaku [5].

Pada kondisi tertentu, orang lain tidak dapat menggantikan peran orangtua sebagai pengasuh anak. Dengan kata lain, orang tua mempunyai peran yang sangat penting dalam menentukan arah serta mutu pertumbuhan dan perkembangan anak. Oleh karena itu, kemampuan orang tua dalam memenuhi kebutuhan akan asah, asih dan asuh melalui komunikasi yang baik dan benar, akan mempengaruhi mutu kepribadian anak menuju manusia dewasa di kemudian hari [6].

Anak-anak yang lahir dengan jarak kelahiran 3 sampai 5 tahun dengan kelahiran sebelumnya memiliki tingkat kelangsungan hidup 2,5 kali lebih tinggi dari pada mereka yang lahir dengan jarak kelahiran $<2$ tahun. Anak-anak yang lahir dengan jarak kelahiran 3 tahun dengan kelahiran sebelumnya lebih sehat saat mereka dilahirkan dan memiliki kemungkinan hidup lebih baik pada setiap pertumbuhan dan perkembangannya [7]. Dengan pengaturan jarak kelahiran resiko malnutrisi berkurang karena ibunya relatif lebih sehat dan mempunyai cukup waktu untuk pengasuhan anaknya (pemberian asuh, asih dan asah). Kemungkinan anak tersebut akan hidup dalam lingkungan yang kaya akan stimulasi yang akan menyebabkanya tumbuh dan berkembang optimal baik secara fisik, mental, maupun psikologi [8]

\section{B. METODE PENELITIAN KONSEP DAN PENDEKATAN TUMBUH KEMBANG ANAK}

\section{a. Sumber Data}

Analisis ini menggunakan data sekunder, yaitu data dari "Survei Indikator Kinerja Rencana Pembangunan Jangka Menengah Nasional (RPJMN) Program Kependudukan dan Keluarga Berencana Tahun 2017”. Survei ini merupakan suatu evaluasi terhadap suatu program yang sedang berjalan, yaitu untuk melihat kegiatan dan hasil pelaksanaan program dilapangan. Survei dilaksanakan di semua kabupaten (34 kabupaten) disumatera utara.

Kerangka sampel yang digunakan dalam survei indikator (RPJMN) program kependudukan dan keluarga berencana tahun 2017 terdiri dari dua tahap. Kerangka sampel tahap pertama adalah seluruh cluster yang disertai informasi jumlah rumah tangga/jumlah keluarga disetiap cluster hasil sensus penduduk (sp) 2010 yang telah mengalami updating. Berdasarkan kerangka sampel tahap pertama ditentukan sejumlah cluster secara probability proportionaltosize (pps), yaitu terpilih 78 cluster di Sumatera Utara. Kerangka sampel tahap kedua hasil listing seluruh keluargadi setiap cluster terpilih. Berdasarkan kerangka sampel tahap kedua ditentukan 35 keluarga secara sistematik random sampling disetiap cluster terpilih. Pelaksanaan pengumpulan data survei indikator (RPJMN) program kependudukan dan keluarga berencana tahun 2017 dilakukan pada bulan pebruarimei 2017.

\section{b. Data Dan Informasi Yang Dianalisis}

Pada survei indikator kinerja RPJMN Program Kependudukan dan Keluarga Berencana Tahun 2017, Responden adalah ibu yang memiliki anak balita dengan usia o-4 tahun dengan jarak kelahiran dari anak terakhir dengan anak sebelumya. Populasi berdasarkan data dieroleh jumlah WUS yang berhasil diwawancarai 10.336 WUS dari seluruh WUS yang ada dicluster terpilih. Jumlah Resonden WUS yang punya anak adalah 1.024, WUS yang memiliki anak baita adalah 607 dan WUS yang memiliki anak balita dengan usia 0-4 tahun dengan jarak kelahiran anak terakhir dengan anak sebelumnya adalah 339.

Beberapa alasan ketidak berhasilan wawancara karena responden tidak ada dirumah, wawancara selesai 
sebagian, responden menolak diwawancara, dan responden tidak mampu menjawab. Data dan informasi yang dianalisis terdiri dari: 1) Data dan informasi tentang jarak kelahiran anak 2) perlakuan keluarga dalam pengasuhan dan tumbuh kembang anak usia 0-4 tahun.

\section{c. Pengolahan dan Analisis Data}

Pengolahan data pada analisis ini menggunakan program SPSS. Sebelum melakukan kategorisasi terlebih dahulu melakukan pembobotan dan mencari nilai indeks. Pada aspek tumbuh kembang fisik: variabel anak diukur tinggi dan berat badannya,anak diajari berprilaku hidup sehat dan lainnya diberibobot 1 (satu), variabel anak diimunisasi dan anak diobati jika sakit diberi bobot2 (dua), kemudian variabel anak diberimakanan bergizi, anak diberi ASI dan anak diberi vitamin diberi bobot 3 (tiga). Pada aspek tumbuh kembang jiwa/mental/spiritual variabel menemani anak bermain, menemani anak belajar, mengajari anak mengucapkan terimakasih, dan lainnya diberi bobot 1 (satu), variabel orang tua sebagai teladan/panutan, mengajari anak untuk menghormati/ menghargai orang lain diberi bobot 2 (dua), kemudian variabel menstimulasi/memacu kreatifitas anak dan mengajari anak beribadah diberi bobot 3( tiga). Pada aspek tumbuh kembang sosial, variabel anak diikutkan lomba dan lainnya diberi bobot 1 (satu), variabel memberi kesempatan bermain dengan teman sebaya dan anak dikursuskan diberi bobot 2 (dua), kemudian variabel anak disekolahkan diberi bobot 3 (tiga). Selanjutnya, dari setiap aspek tumbuh kembang anak (aspek fisik, jiwa dan sosial) masing-masing dengan bobot 6 (enam) yang merupakan penjumlahan dari nilai bobot tiap variabel yang sudah dijelaskan diatas $(1+2+3=6)$.

Nilai indeks untuk partisipasi orangtua dalam pengasuhan dan tumbuh kembang anak usia o-6 tahun berkisar antara o-10o. Nilai indeks tersebut diperoleh dari rumus yang disajikan sebagaiberikut:

$$
Y=\frac{X-\text { Nilai Minimum } X}{\text { Nilai Maksimum } X-\text { Nilai Minimum X }} \times 100
$$

\section{Keterangan :}

$\mathrm{Y}=$ NilaiIndeks

$\mathrm{X}=$ Skor yang diperoleh untuk setiap sampel/responden

\section{d. Tabel 1. Pembobotan variabel}

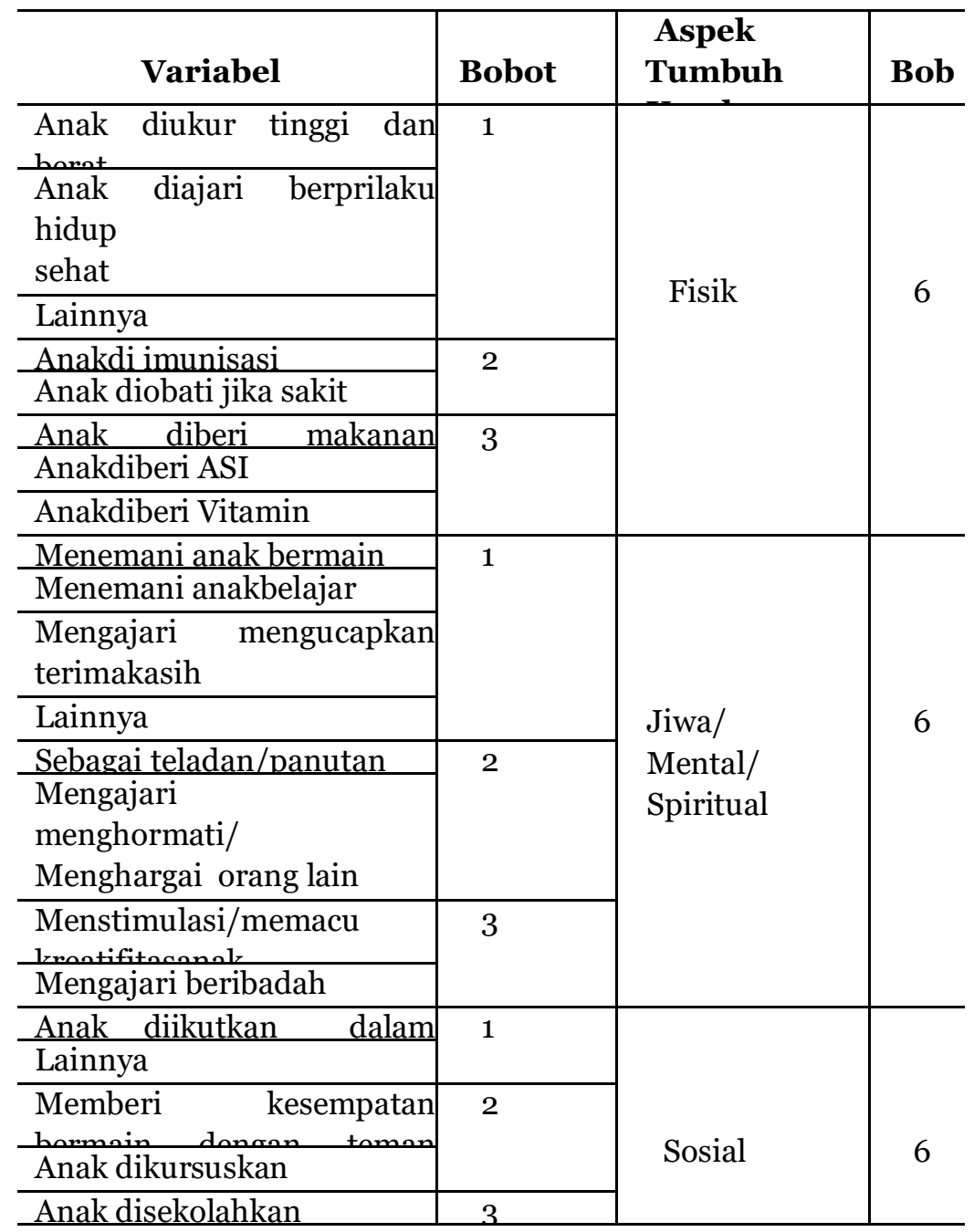


Setelah memperoleh nilai indeks partisipasi keluarga dalam pengasuhan dan tumbuh kembang anak, nilai indeks tersebut dikelompokkan/dikategorikan menjadi 3 (tiga) kategori yaitu kurang, sedang dan baik. Sehingga diperoleh nilai interval 33,33. Kategori kurang dengan nilai (o-33,33), kategori sedang

\section{d. Karakteristik Keluarga}

Menurut lokasi tempat tinggal, pada analisis ini keluarga yang tinggal di pedesaan lebih banyak dibandingkan keluarga yang tinggal di perkotaan, masing-masing sebesar 74.0 persen dan 26.0 persen. Umur WUS yang menjadi responden 23-29 Tahun sebesar persen, 30-36 Tahun sebesar 48.7 persen, 37 43Tahun sebesar 35.1 persen dan 44-50 Tahun sebesar 5.3 persen. Status Perkawinan WUS pada analisis ini adalah yang menikah sebesar 98.5 persen (sebanyak 334 responden), hidup bersama dengan pasangan sebesar 0.3 persen (sebanyak 1 responden), dan cerai mati sebesar 1.2 persen (sebanyak 4 responden). Jumlah Kelahiran pada analisis ini dibagi menjadi tiga kategori; pendek <2 Tahun Sebesar o persen, normal 2-4 tahun sebesar 72.6 persen sedangankan kategori panjang $>5$ tahun sebesar 27.5 persen.

\section{e. Aspek Pertumbuhan Fisik.}

Pertumbuhan adalah perubahan ukuran dan bentuk tubuh atau anggota tubuh, yaitu: bertambahnya berat badan, bertambahnya tinggi badan, bertambahnya lingkaran kepala, tumbuh dan tanggalnya gigi susu dan gigi tetap perubahan tubuh lainnya. Contoh: 1) Berat badan: berat bayi dalam kandungan 6 bulan biasanya 650 gr, pada waktu lahir menjadi 3.000 gr, pada waktu satu tahun bertambah menjadi $10 \mathrm{~kg}$ dan waktu dewasa mencapai $53 \mathrm{~kg}$. 2) Tinggi atau panjang badan: panjang bayi waktu dalam kandungan 6 bulan kira-kira $30 \mathrm{~cm}$, waktu dilahirkan panjangnya $48 \mathrm{~cm}$, pada waktu satu tahun menjadi $75 \mathrm{~cm}$, dan saat dewasa tingginya menjadi $160 \mathrm{~cm}$ (DITBALNAK-BKKBN 2015). Hasil analisis menunjukkan bahwa keluarga yang melakukan pengukuran tinggi berat badan 17.4 persen (sebanyak 59 responden).

Asupan makanan yang diberikan orangtua pada anak berhubungan dengan status gizi anak (Purwaningrum \&Wardani, 2012). Hasil analisis menunjukkan bahwa keluarga yang memberikan dan memperhatikan makanan bergizi seimbang sebesar 32.4 persen (sebanyak 110 responden).

Peraturan Menteri Kesehatan RI No.42 Tahun 2013 tentang penyelenggaraan imunisasi, mendefinisikan imunisasi sebagai suatu upaya untuk menimbulkan/meningkatkan kekebalan seseorang secara aktif terhadap suatu penyakit, sehingga bila suatu saat terpajan dengan penyakit tersebut tidak akan sakit atau hanya mengalami sakit ringan. Imunisasi rutin dan sifatnya dasar yang diberikan pada bayi sebelum berusia 1 (satu) tahun antara lain: Bacillus Calmette Guerin
(33,33-66,67), dan kategori baik (66,67-100). Analisis data dilakukan dengan mengelompokkan aspek tumbuh kembang anak dan pembobotan nilai dengan pengelompokan kategori jarak kelahiran kemudian disajikan dengan tabel silang. Menguji hubungan kedua variabel dilakukan dengan uji Chi Square.

(BCG), Diphtheria Pertusis Tetanus-Hepatitis B (DPT-HB) atau Diphtheria Pertusis Tetanus-Hepatitis B-Hemophilus Influenza Type B (DPT-HB- Hib), Hepatitis B pada bayi baru lahir, polio dan campak. Sedangkan imunisasi lanjutan yang dapat diberikan pada anak usia di bawah tiga tahun (Batita) berupa: Diphtheria Pertusis Tetanus-Hepatitis B (DPT- HB) atau Diphtheria Pertusis Tetanus- Hepatitis BHemophilus Influenza Type B (DPT-HB-Hib) dan campak.dan itulah sebabnya pada pembobotan pemebrian makanan bergizi, asi dan vitamin lebih tinggi bobotnya, karena hal ini merupakan kebutuhan yang harus dipenuhi untuk memenuhi pertumbuhan fisik pada anak balita. Hasil analisis menunjukkan bahwa keluarga yang memberikan imunisasi sebesar 26.8 persen (sebanyak 91 responden).

Menurut WHO, ASI merupakan makanan ideal bagi bayi pada 6 bulan pertama kehidupannya. Bayi dikategorikan mendapat ASI eksklusif jika bayi mendapat Air Susu Ibu selama enam bulan pertama setelah kelahiran tanpa mendapatkan makanan dan minuman tambahan.

Hasil penelitian Tamimi, Jurnalis \& Sulastri (2016) menunjukkan bahwa terdapat hubungan yang bermakna antara pemberian ASI eksklusif dengan kejadian diare. Jarak kelahiran yang pendek membuat anak tidak mendapatkan ASI eksklusif secara maksimal. Kejadian diare pada bayi yang diberikan ASI eksklusif cenderung lebih rendah dibandingkan pada bayi non ASI eksklusif. Bayi yang disusui dengan durasi 6 bulan atau lebih memiliki ketahanan hidup 33,3 kali lebih baik daripada bayi yang disusui kurang dari 4 bulan, dan bayi yang disusui dengan durasi 4-5 bulan memiliki ketahanan hidup 2,6 kali lebih baik daripada bayi yang disusui kurang dari 4 bulan. Hasil analisis menunjukkan bahwa keluarga yang memberikan ASI sebesar 30.4 persen (sebanyak 103 responden) (8).

Pemberian vitamin pada anak sangat penting untuk dilakukan oleh orang tua. Hasil penelitian yang dilakukan Tjekyan (2015) menunjukkan bahwa diare pada balita yang mendapat suplementasi vitamin A lebih cepat sembuh dibandingkan balita yang tidak mendapat suplementasi vitamin A. Hasil analisis menunjukkan bahwa keluarga yang memberikan vitamin adalah sebesar 18.0 persen ( sebanyak 61 responden) (9).

Mengobati anak yang sedang sakit seperti sakit pilek, batuk, dan demam merupakan bagian dari pengasuhan orang tua dalam tumbuh kembang anak dari aspek fisik. Pada umumnya, orang tua yang 
memiliki anak usia kurang dari setahun akan segera membawa anaknya untuk berobat apabila sakit batuk dan pilek karena beranggapan bahwa anak masih dalam kondisi lemah, hal ini akan berbeda dengan orang tua yang memiliki anak balita yang sudah lebih besar. Hasil analisis menunjukkan bahwa keluarga yang mengobati anak ketika sedang sakit adalah sebesar 22.7 persen (sebanyak 77 responden).

Orang tua membiasakan anak untuk berperilaku hidup sehat dengan cara: minum air matang, memcuci makanan sampai bersih, menutup makanan dengan baik, membiasakan diri mencuci dan mandi teratur, cukup istirahat, cukup berolahraga/kegiatan/ bermain/ dan cukup rekreasi (DITBALNAK-BKKBN 2015) (10). Hasil analisis menunjukkan bahwa keluarga yang mengajari anak berprilaku hidup sehata adalah sebesar 6.2 persen (sebanyak 21 responden).

Tabel.2 Aspek Pertumbuhan Fisik

\begin{tabular}{lll}
\hline \multirow{2}{*}{ Kategori } & \multicolumn{2}{l}{ Aspek Pertumbuhan Fisik } \\
\cline { 2 - 3 } & $\mathrm{f}$ & $\%$ \\
\hline Kurang & 312 & 92 \\
Baik & 27 & 8 \\
Total & 339 & 100 \\
\hline
\end{tabular}

Berdasarkan tabel. 2 mengenai aspek pertumbuhan fisik diperoleh bahwa sebesar 92 persen kurang optimal dalam memperhatikan pertumbuhan fisik anak. Dan responden yang sudah optimal dalam memperhatikan kondisi fisik anak sebesar 8 persen.

\section{Aspek Perkembangan Jiwa/Mental/ Spiritual.}

Kemampuan dan tumbuh kembang anak perlu dirangsang oleh orang tua agar anak dapat tumbuh dan berkembang secara optimal sesuai dengan umurnya. Stimulasi adalah perangsangan (penglihatan, bicara, pendengaran, perabaan) yang datang dari lingkungan anak. Anak yang mendapat stimulasi yang terarah akan lebih cepat berkembang dibandingkan anak yang kurang bahkan tidak mendapat stimulasi. Hasil analisis menunjukkan bahwa keluarga yang menstimulasi/memacu kreatifitas anak adalah sebesar 9.1 persen (sebanyak 31 responden).

Menemani anak bermain dan belajar merupakan hal yang penting dilakukan oleh orang tua agar anak dapat tumbuh dan berkembang secara optimal. Manfaat dari orangtua menemani anak bermain dan belajar diantaranya anak merasa diperhatikan dan dekat dengan orangtuanya sehingga anak merasa aman dan nyaman. Selain itu, orangtua ada yang mengarahkan anak sehingga memperoleh wawasan yang benar ketika ia bermain dan belajar. Hasil analisis menunjukkan bahwa keluarga yang menemani anak bermain adalah sebesar 23.3 persen (sebanyak 79 responden).

Orang tua adalah pendidik paling utama dan pertama dalam memberikan pendidikan kepada anaknya. Seorang anak sangat membutuhkan sosok teladan agar anak nantinya memiliki kepribadian yang kuat untuk menghadapi kehidupannya di masa mendatang. Ada ungkapan " anak-anak mendengar tidak dengan telinga, melainkan dengan matanya”, artinya orangtua harus menjadi contoh nyata/konkrit bagaimana dalam bersikap sebelum meminta anak untuk melakukan tindakan yang diinginkannya. Hasil analisis menunjukkan bahwa keluarga yang menjadi teladan/panutan adalah sebesar 16.8 persen (sebanyak 57 responden).

Mengajari ibadah, mengucapkan terima kasih dan mengoharmati orang lain merupakan nilai positif yang perlu diajarkan oleh orang tua agar anak memiliki kepribadian yang baik. Hasil analisis menunjukkan bahwa keluarga yangmengajari beribadan dan mengucapkan terima kasih adalah sebesar 45.7 persen (sebanyak 155 responden).

Tabel. 3 Aspek Jiwa/Mental/Spiritual

\begin{tabular}{llc}
\hline \multirow{2}{*}{ Kategori } & \multicolumn{2}{c}{ Aspek Jiwa/Mental/Spiritual } \\
\cline { 2 - 3 } & $\mathrm{f}$ & $\%$ \\
\hline Kurang & 306 & 90.3 \\
Baik & 33 & 9.7 \\
Total & 339 & 100 \\
\hline
\end{tabular}

Berdasarkan tabel. 3 mengenai Aspek Jiwa/Mental/Spiritual maka dapat dilihat bahwa responden yang memberikan dukungan jiwa/mental/spiritual yang baik kepada anak sebanyak 33 responden dan yang kurang mendukung sebanyak 306 responden.

\section{Aspek Perkembangan Sosial.}

Memberi kesempatan anak untuk bermain merupakan cara orang tua agar anak bisa bergaul dan mandiri. Interaksi dengan teman sebaya akan membuka pandangan baru pada anak dan memberi kebebasan mereka untuk membuat keputusan. 
Hasil analisis menunjukkan bahwa cukup banyak keluarga yang memberikan kesempatan bermain dengan teman sebaya. Menurut Istiyani (2013), melalui bermain anak dapat mengenal aturan, bersosialisasi, menempatkan diri, menata emosi, toleransi, kerja sama, mengalah, sportif, dan sikapsikap positif lainnya. Hasil analisis menunjukkan bahwa keluarga yang memberikan kesempatan anak untuk bermain dengan teman sebaya adalah sebesar 33.9 persen (Sebanyak 115 responden).
Sekolah dan tempat kursus merupakan suatu tempat yang dapat digunakan untuk mengembangkan kecerdasan pikiran dan pengetahuan, selain itu dapat digunakan sebagai tempat pembelajaran sosialisasi bagi anak. Anak akan belajar bergaul dengan sesama peserta didik di sekolah atau di tempat kursus, dengan guru dan dengan karyawan yang ada di sekolah atau tempat kursus. Hasil analisis menunjukkan bahwa keluarga yang mensekolahkan dan menkursuskan adalah sebesar 31.9 persen (sebanyak 108 responden).

Tabel. 4 Aspek Perkembangan Sosial

\begin{tabular}{lcc}
\hline \multirow{2}{*}{ Kategori } & \multicolumn{2}{c}{ Aspek Perkembangan Sosial } \\
\cline { 2 - 3 } & $\mathrm{f}$ & $\%$ \\
\hline Kurang & 266 & 78.5 \\
Baik & 73 & 21.5 \\
Total & 339 & 100 \\
\hline
\end{tabular}

Berdasarkan Tabel. 4 mengenai aspek sosial maka dapat dilihat bahwa sebanyak 73 responden dapat memberikan dan mengajarkan perkembangan sosial yang baik, sedangkan 266 responden yang lain masih kurang dalam memberikan dan mengajarkan perkembangan sosial tersebut.

Tabel 5. Jarak Kelahiran Anak

Jarak kelahiran dibagi menjadi 2 kategori; pendek adalah <2 Tahun dan panjang adalah >2 Tahun.

\begin{tabular}{lcc}
\hline \multirow{2}{*}{ Kategori } & \multicolumn{2}{c}{ Jarak Kelahiran } \\
\cline { 2 - 3 } & $\mathrm{f}$ & $\%$ \\
\hline Pendek & 82 & 24.2 \\
Panjang & 257 & 75.8 \\
Total & 339 & 100 \\
\hline
\end{tabular}

Dari total responden sebanyak 339 responden (100\%) diperoleh orangtua yang memiliki anak dengan jarak kelahiran pendek sebanyak 82 responden (24,2\%).
Sedangkan orangtua yang memiliki anak jarak kelahiran panjang adalah sebanyak 257 responden (75,8\%).

Tabel 6. Hasil Analisis Bivariat antara Jarak Kelahiran Dengan Pengasuhan Tumbuh Kembang Anak

\begin{tabular}{lccccccc}
\hline \multirow{2}{*}{$\begin{array}{l}\text { Jarak } \\
\text { Kelahiran }\end{array}$} & \multicolumn{9}{l}{ Tumbuh Kembang Anak } & \multirow{2}{*}{ Sig } \\
\cline { 2 - 7 } & Kurang & \multicolumn{3}{c}{ Baik } & \multicolumn{3}{l}{ Total } \\
\cline { 2 - 7 } & $\mathrm{f}$ & $\%$ & $\mathrm{f}$ & $\%$ & $\mathrm{f}$ & $\%$ & \\
\hline Pendek & 65 & 79.3 & 17 & 20.7 & 82 & 100 & \\
Panjang & 216 & 84 & 41 & 16 & 257 & 100 & 0.201 \\
Total & 281 & 82.9 & 58 & 17.1 & $\mathbf{3 3 9}$ & & \\
& & & & & & 100 & \\
\hline
\end{tabular}

Dari total 339 responden (100\%) diperoleh 82 responden yang memiliki anak dengan jarak kelahiran pendek terdapat $65 \quad(79,3 \%)$ responden yang pengasuhan tumbuh kembangnya kurang baik. Dan 17 (20,7\%) responden yang pengasuhan tumbuh kembangnya baik. Sementara itu, dari 257 responden yang memiliki anak dengan jarak kelahiran panjang terdapat 216 (84\%) responden yang pengasuhan tumbuh kembangnya kurang baik. Dan 41 (16\%) responden yang pengasuhan tumbuh kembangnya baik. Dan dari hasil uji chi square diperoleh nilai sig o.201 yang menunjukkan bahwa tidak ada hubungan jarak kelahiran dengan pengasuhan tumbuh kembang anak di sumatera utara. 


\section{PEMBAHASAN}

\section{Hubungan jarak kelahiran dengan pengasuhan tumbuh kembang anak di Sumatera Utara}

Setiap anak yang lahir ke dunia haruslah diasuh dengan baik. 1000 hari pertama kehidupannya merupakan periode yang tepat untuk mengoptimalkan tumbuh kembangnya. Tata cara pengasuhan yang tepat yang diberikan oleh orangtua kepada anak merupakan bekal bagi anak untuk membuat anak tersebut menjadi baik. Jarak kelahiran dalam keluarga juga menjadi hal yang penting untuk orangtua agar dapat mengasuh anak dengan baik. Jarak kelahiran yang pendek dapat membuat anak terabaikan dikarenakan kedua orangtua tidak bisa mengasuh secara optimal. Sementara itu, jarak kelahiran yang panjang dianggap bisa membuat asuhan orangtua menjadi optimal. Pola asuh anak yang kurang optimal akan berdampak pada tumbuh kembang anak terutama di periode emas balita.

Pertumbuhan adalah perubahan ukuran dan bentuk tubuh atau anggota tubuh, yaitu: bertambahnya berat badan, bertambahnya tinggi badan, bertambahnya lingkaran kepala, tumbuh dan tanggalnya gigi susu dan gigi tetap perubahan tubuh lainnya. Perkembangan adalah kematangan yang terjadi pada sel-sel tubuh manusia menuju kedewasaan seperti dari bayi menuju balita.

Penelitian ini menunjukkan bahwa tidak ada hubungan yang signifikan antara jarak kelahiran dengan pengasuhan tumbuh kembang anak di Sumatera Utara. Hal ini membuktikan bahwasanya tidak ada perbedaan pengasuhan orang tua baik pada jarak kelahiran pendek maupun jarak kelahiran yang panjang. Sedangkan menurut Hasil penelitian Tamimi, Jurnalis \& Sulastri (2016) menunjukkan bahwa terdapat hubungan yang bermakna antara pemberian ASI eksklusif dengan kejadian diare. Jarak kelahiran yang pendek membuat anak tidak mendapatkan ASI eksklusif secara maksimal. Kejadian diare pada bayi yang diberikan ASI eksklusif cenderung lebih rendah dibandingkan pada bayi non ASI eksklusif (8).

Menurut asumsi peneliti, hal ini terjadi dikarenakan orangtua tidak terlalu mementingkan pengasuhan tumbuh kembang anak yang meliputi aspek pertumbuhan fisik, aspek jiwa/metal/spiritual dan aspek sosial. Namun orangtua lebih mementingkan aspek finansial atau keuangan mereka. Sehingga pola asuh menjadi terabaikan.

Keadaan ini bukanlah suatu kondisi yang baik. Dikarenakan semakin panjang jarak kelahiran anak maka semakin baik pula pola asuh tumbuh kembang yang diberikan oleh orangtua kepada anak. Sebaliknya apabila jarak kelahiran pendek maka pola asuh tumbuh kembang anak menjadi kurang maksimal.

\section{KESIMPULAN}

Hasil analisis bivariat penelitian diperoleh bahwasanya tidak ada hubungan yang signifikan antara jarak kelahiran dengan pengasuhan tumbuh kembang anak. Terdapat 3 (tiga) aspek di dalam pengasuhan tumbuh kembang anak yaitu aspek pertumbuhan fisik, aspek jiwa/mental/spiritual dan aspek sosial. Ketiga aspek tersebut tidak memiliki hubungan yan gsignifikan dengan pengasuhan tumbuh kembang anak di Sumatera Utara. Sehingga tidak ada perbedaan antara jarak kelahiran panjang maupun pendek dengan pengasuhan tumbuh kembang anak. Hal ini disebabkan oleh faktor-faktor lain seperti faktor pendidikan, pengetahuan dan faktor status ekonomi yang perlu diteliti lebih lanjut untuk melihat hubungan faktor tersebut dengan pengasuhan tumbuh kembang anak.

\section{UCAPAN TERIMA KASIH}

Penulis mengucapkan terima kasih kepada Kepala Pusat Penelitian dan Pengembangan KB dan Keluarga Sejahtera - Badan Kependudukan dan Keluarga Berencana Nasional (BKKBN) yaitu Tengku Lafalinda, M.Pd, yang telah memberikan ijin menggunakan data "Survei Indikator Kinerja Rencana Pembangunan Jangka Menengah Nasional (RPJMN) Program Kependudukan dan Keluarga Berencana Tahun 2017" kepada penulis untuk analisis ini.

\section{DAFTAR PUSTAKA}

[1] Istiyani D. Model pembelajaran membaca menulis menghitung (calistung) pada anak usia dini di kabupaten pekalongan. J Penelit. 2014;10(1).

[2] Kependudukan B, Nasional KB. Bina Keluarga Balita dan Anak (2013). Menjadi Orang Tua Hebat dalam Mengasuh Anak (usia 0-6 tahun) Di akses dari www slideshare net-menjadi-orang-tua-hebat-buku-1-binakeluarga-balita Diakses tanggal. 2015;20.

[3] Nurmiati B. Pengaruh durasi pemberian ASI terhadap ketahanan hidup bayi di Indonesia. Makara Kesehat. 2008;12(2).

[4] Rahadian AS. Pemenuhan Hak Asi Eksklusif Di Kalangan Ibu Bekerja: Peluang Dan Tantangan (Fulfilling The Right For Exclusive Breastfeeding Among Working Women: Opportunities And Challenges). J Kependud Indones. 2017;9(2):107-16.

[5] Puspitawati H. Gender dan keluarga: konsep dan realita di Indonesia. Bogor IPB Press 26 Novemb 2017] Tersedia pada http//ikk fema ipb ac id/v2/images/karyailmiah/gender pdf. 2012;

[6] Rahayu Fsri. Hubungan Antara Jarak Kelahiran Yang Dekat Dengan Tingkat Pekembangan Anak Usia 1-3 Tahun Di Wilayah Kerja Puskesmas Andong Boyolali. Universitas Muhammadiyah Surakarta; 2009.

[7] Oktriyanto NFN. Partisipasi Keluarga Anggota Bina Keluarga Balita (Bkb) Dalam Pengasuhan Dan Tumbuh Kembang Anak Usia o-6 Tahun. J Kependud Indones. 2017;11(2):133-42.

[8] Tamimi MA, Jurnalis YD, Sulastri D. Hubungan pemberian ASI eksklusif dengan kejadian diare pada bayi di wilayah Puskesmas Nanggalo Padang. J Kesehat Andalas. 2016;5(1).

[9] Tjekyan S. Pengaruh Suplementasi Vitamin A Terhadap Lama Diare pada Anak Usia 12-51 Bulan yangBerobat di Puskesmas Sukarami Palembang. J Kedokt dan Kesehat. 2015;2(2). 
[10] BKKBN)., Direktorat Bina Keluarga Balita dan Anak (DITBALNAK) - Badan Kependudukan dan Keluarga Berencana Nasional. : Menjadi Orangtua Hebat dalam Mengasuh Anak (Usia o-6 Tahun. Jakarta: D. 2015.

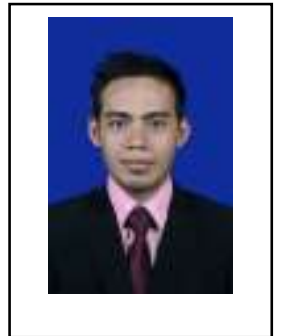

sebagai

\section{PROFIL PENULIS UTAMA}

Asrul, S.Pd.I., M.Pd, saya adalah seorang dosen tetap di Institut Kesehatan Helvetia Medan dan aktif bekerja sejak tahun 2015 . Sejak berkecimpung didunia pendidikan saya juga aktif berbagi ilmu di dikelas inspirasi dan Akuntabilitas Program KKBPK BKKBN Provinsi Sumatera Utara Sejak Tahun 2016 sampai sekarang. Dalam hal pengalaman menulis, hasil tulisan yang sudah dipublikasikan sebelumnya adalah mengenai Pengembangan Media Pembelajaran Interaktif Mata Pelajaran Bahasa Inggris pada anaka Sekolah Dasar, Hubungan Persepsi Ibu Tentang Hypnobirthing Dengan Pengurangan Rasa Nyeri Pada Ibu Bersalin Normal Di Klinik Diana Medan Tahun 2018. Dan Police Brief mengenai Survei Indikator Kinerja Program Kependudukan Keluarga Berencana dan Pembangunan Keluarga Indikator Rencana Pembangunan Jangka Menengah Nasional (RPJMN) Provinsi Sumater4a Utara Tahun 2017. Untuk mengembangkan diri saya memperdalam keterampilan dalam bidang Hypnotherapy dan NLP serta Public Speaking. 